J. Electroanal. Chem., 290 (1990) 181-189

Elsevier Sequoia S.A., Lausanne

\title{
Vibrational analysis of interfacial phosphate equilibria
}

\author{
Vicki Berger Paulissen and Carol Korzeniewski \\ Department of Chemistry, The University of Michigan, Ann Arbor, MI 48109 (U.S.A.)
}

(Received 20 November 1989; in revised form 9 April 1990)

\begin{abstract}
Potential dependent changes in $\mathrm{pH}$ were observed at the platinum/solution interface by monitoring changes in the equilibrium concentration of phosphates using infrared spectroscopy. The $\mathrm{pH}$ at the platinum/solution interface was observed to decrease with increasing positive potentials in alkaline solutions. At potentials in the oxide region of platinum, changes in the composition of bulk solution arise owing to the formation of surface oxides. The potential dependent $\mathrm{pH}$ changes observed in these studies are consistent with theories concerning the interfacial properties of hydrogen adsorbing metals. Such potential dependent $\mathrm{pH}$ changes may have important consequences when studying the electrochemical reactivity of compounds which are sensitive to $\mathrm{pH}$.
\end{abstract}

\section{INTRODUCTION}

Phosphates are common supporting electrolytes for electrochemical investigations and are most often employed in studies concerning fuel cell development [1,2] and biological redox chemistry [3]. The adsorption properties of phosphates at metal electrodes are of fundamental importance and have been the subject of several investigations $[1,2,4,5]$. Early studies employed radiotracer methods to investigate adsorption over a range of electrode potentials [4,5]. Studies performed under conditions where $\mathrm{H}_{2} \mathrm{PO}_{4}^{-}$was the dominant anion in solution revealed that adsorption begins at potentials just positive of the hydrogen region, and increases with increasing positive potential into the oxide region, at which point desorption begins [4]. Similar studies were undertaken to understand the adsorption behavior of phosphoric acid on metal electrodes [1,2,5]. Electrolyte solutions containing phosphoric acid have been shown to improve the performance of fuel cells, and more recent investigations by in situ infrared spectroscopy have confirmed the potential dependent adsorption behavior of phosphoric acid established by radiotracer studies $[1,2]$.

\footnotetext{
‡ To whom correspondence should be addressed.
} 
Although radiotracer methods are sensitive to trace quantities of adsorbed material, they cannot distinguish between the various $\mathrm{pH}$ dependent forms of the ion. This becomes important when adsorption at platinum electrodes is studied, as the interfacial structure of hydrogen adsorbing electrodes is a function of $\mathrm{pH}$ [6], and, as a result, the equilibrium distribution of ions at the surface of platinum electrodes can be altered from that in solution. Indeed, recent in situ infrared spectroscopic investigations into the potential dependent adsorption of sulfate and bisulfate at platinum electrodes revealed that, under mildly acidic conditions, the activity ratio of adsorbed ions differed from the activity ratio of ions in solution [7]. Surface enhanced Raman studies of phosphate adsorption on silver electrodes present further evidence that conditions near the surface can be different from those in solution [8]. In the present work, we demonstrate that potential dependent changes in interfacial $\mathrm{pH}$ are observed at platinum electrodes in alkaline solutions (pH 13 and $\mathrm{pH} \mathrm{10)} \mathrm{containing} \mathrm{phosphate} \mathrm{electrolytes.}$

\section{EXPERIMENTAL}

Infrared spectroscopic measurements were performed using a Digilab FTS-40 Fourier transform infrared (FTIR) spectrometer. A thin layer spectroelectrochemical cell was positioned in the sample compartment such that infrared radiation was specularly reflected from the surface of the working electrode. Spectra were collected using potential modulation to ensure optimal signal-to-noise ratios. The potential of the working electrode was switched between the reference and base potentials every 32 scans until a total of 256 interferograms were collected and signal averaged at each potential. The base potential used throughout these experiments was $-0.25 \mathrm{~V}$ (SCE). All in situ spectra are displayed in units of $\Delta R / R$.

Spectroelectrochemical cells were constructed from Kel-F using a design similar to that previously reported [9]. A hemispherical zinc selenide window (Harrick) was employed to allow the angle of incidence at the electrode/solution interface to be adjusted to ca. $68^{\circ}$. The working electrode was constructed from a disk of platinum ( $6 \mathrm{~mm}$ diameter). The disk was sealed in the end of a glass tube and polished to a mirror finish using alumina polishing powder of $1,0.3$, and $0.05 \mu \mathrm{m}$. A saturated calomel reference electrode was located in a compartment which was separated from the main sample chamber by a glass stopcock and connected via a Luggin capillary. All potentials are reported with respect to the saturated calomel electrode (SCE).

Solutions were prepared from $\mathrm{Na}_{3} \mathrm{PO}_{4} \cdot 12 \mathrm{H}_{2} \mathrm{O}$ (Aldrich) and adjusted to the proper $\mathrm{pH}$ with $\mathrm{NaOH}$ or $\mathrm{H}_{3} \mathrm{PO}_{4}$. Nanopure water (Barnsted Nanopure system) was used throughout. Solutions were degassed by bubbling with argon prior to experiments.

\section{RESULTS AND DISCUSSION}

Phosphoric acid is triprotic with acid dissociation constants ( $\mathrm{p} K_{\mathrm{a}}$ values) 2.14, 7.2 and 12.4, for $\mathrm{H}_{3} \mathrm{PO}_{4}, \mathrm{H}_{2} \mathrm{PO}_{4}^{-}$and $\mathrm{HPO}_{4}^{2-}$, respectively. At $\mathrm{pH} 13, \mathrm{PO}_{4}^{3-}$ and 


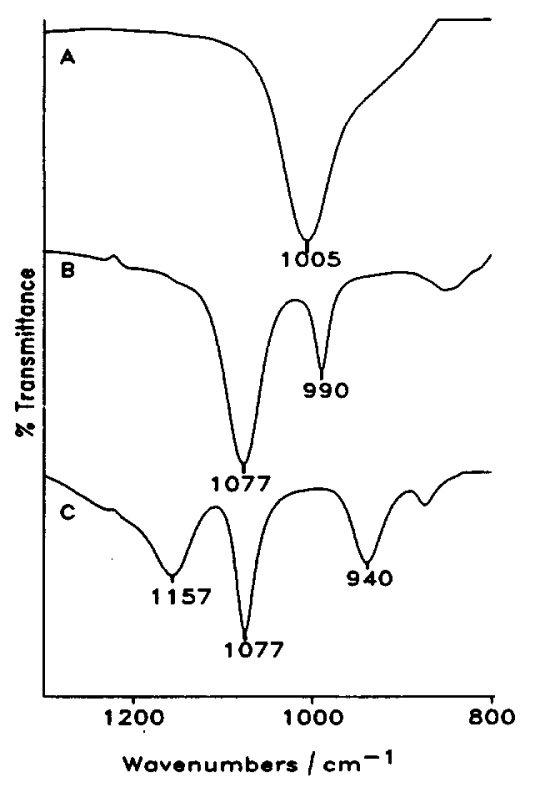

Fig. 1. Transmission spectra of various forms of phosphate showing $\nu_{3}$ of solutions containing (A) $0.1 \mathrm{M}$

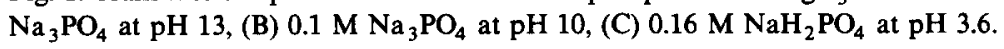

$\mathrm{HPO}_{4}^{2-}$ are the principle phosphate species in solution with the concentration ratio $\left[\mathrm{PO}_{4}^{3-}\right] /\left[\mathrm{HPO}_{4}^{2-}\right]=5.0$. At $\mathrm{pH} 10, \mathrm{HPO}_{4}^{2-}$ and $\mathrm{H}_{2} \mathrm{PO}_{4}^{-}$are the principal electrolyte components with the concentration ratio $\left[\mathrm{HPO}_{4}^{2-}\right] /\left[\mathrm{H}_{2} \mathrm{PO}_{4}^{-}\right]=631$. Thus, $\mathrm{PO}_{4}^{3-}$ and $\mathrm{HPO}_{4}^{2-}$ are the dominant forms of phosphate at $\mathrm{pH} 13$ and $\mathrm{pH} 10$, respectively. Shown in Fig. 1 are transmission spectra of solutions containing $0.1 \mathrm{M}$ $\mathrm{Na}_{3} \mathrm{PO}_{4}$ at $\mathrm{pH} 13$ (Fig. 1A), $0.1 \mathrm{M} \mathrm{Na}_{3} \mathrm{PO}_{4}$ at pH 10 (Fig. 1B), and $0.16 \mathrm{M}$ $\mathrm{NaH}_{2} \mathrm{PO}_{4}$ at pH 3.6 (Fig. 1C). The band appearing at $1005 \mathrm{~cm}^{-1}$ in Fig. 1A arises from the triply degenerate $\nu_{3}$ vibrational mode of $\mathrm{PO}_{4}^{3-}[10,11]$. Bands appearing in the spectrum in Fig. 1B are due to vibrations of $\mathrm{HPO}_{4}^{2-}$. These bands arise from the $\nu_{3}$ mode of tetrahedral $\mathrm{PO}_{4}^{3-}$ but are split due to the symmetry perturbation of the protonated form of the ion. This effect is illustrated in the correlation diagram of Table 1 . The $1077 \mathrm{~cm}^{-1}$ band is doubly degenerate and is assigned to the $\nu_{4}$ mode. The $990 \mathrm{~cm}^{-1}$ band correlates with the $\nu_{1}$ mode. Similarly, bands in the

TABLE 1

Correlation of the $\nu_{3}$ vibrational mode of a tetrahedral species as the symmetry is lowered

\begin{tabular}{ll}
\hline Symmetry & Vibrational modes \\
\hline $\mathrm{T}_{\mathrm{d}}$ & $\nu_{3}: \mathrm{F}_{2}(\mathrm{IR}, \mathrm{R})$ \\
$\mathrm{C}_{3 \mathrm{v}}$ & $\nu_{1}: \mathrm{A}(\mathrm{IR}, \mathrm{R}), \nu_{4}: \mathrm{E}(\mathrm{IR}, \mathrm{R})$ \\
$\mathrm{C}_{2 \mathrm{v}}$ & $\nu_{1}: \mathrm{A}(\mathrm{IR}, \mathrm{R}), \nu_{6}: \mathrm{B}_{1}(\mathrm{IR}, \mathrm{R}), \nu_{8}: \mathrm{B}_{2}(\mathrm{IR}, \mathrm{R})$ \\
\hline
\end{tabular}




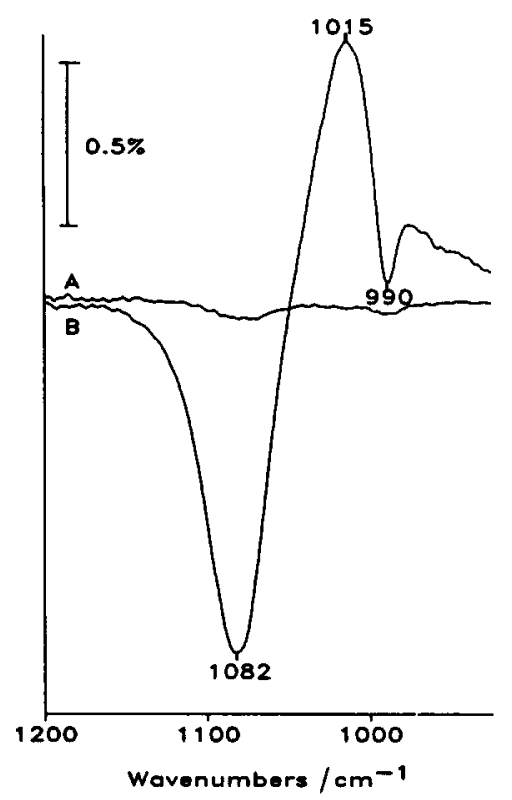

Fig. 2. Infrared spectra collected in situ at $+0.6 \mathrm{~V}$ for a solution containing $0.1 \mathrm{M} \mathrm{Na}{ }_{3} \mathrm{PO}_{4}$ at $\mathrm{pH} 13$ using (A) s-polarized and (B) p-polarized radiation. The base potential was $-0.25 \mathrm{~V}$. Spectra are plotted in transmittance mode.

spectrum of Fig. $1 \mathrm{C}$ are due to vibrations of $\mathrm{H}_{2} \mathrm{PO}_{4}^{-}$, and arise from splitting of the triply degenerate $\nu_{3}$ mode of the $\mathrm{PO}_{4}^{3-}$ anion. The modes occurring at $1157 \mathrm{~cm}^{-1}$, $1077 \mathrm{~cm}^{-1}$ and $940 \mathrm{~cm}^{-1}$ are non-degenerate and are due to the $\nu_{8}, \nu_{6}$, and $\nu_{1}$ modes respectively $[10,11]$.

Shown in Fig. 2 are in situ infrared spectra collected using p-polarized and s-polarized radiation for a $0.1 \mathrm{M} \mathrm{Na}_{3} \mathrm{PO}_{4}$ solution at $\mathrm{pH} 13$. Bands pointing upward correspond to species present at the base potential of $-0.25 \mathrm{~V}$ and bands pointing downward correspond to species present at $+0.60 \mathrm{~V}$. The absence of bands in the s-polarized spectrum suggests that the concentration of species in the thin layer remains constant over this potential range, so that bands appearing in the p-polarized spectrum can be assigned to vibrations of species at or near (in the double layer) the electrode surface. Further, bands in the p-polarized spectrum appear to be shifted in energy by about $10 \mathrm{~cm}^{-1}$ compared to the spectrum of the ions in solution, suggesting the presence of weakly adsorbed ions. The direction and magnitude of the shift are consistent with those observed for ionically perturbed oxo anions [12]. Another interesting feature of this spectrum is the increase in adsorbed $\mathrm{HPO}_{4}^{2-}$ at the more positive potential. The spectrum indicates that, compared to $-0.25 \mathrm{~V}$, the $\mathrm{PO}_{4}^{3-}$ concentration at $+0.6 \mathrm{~V}$ is reduced while the surface $\mathrm{HPO}_{4}^{2-}$ concentration increases. This general trend is observed at potentials throughout the double layer region as shown in Fig. 3. An increase in surface $\mathrm{HPO}_{4}^{2-}$ concentration is observed with increasing positive potential while the amount of surface $\mathrm{PO}_{4}^{3-}$ decreases. The 


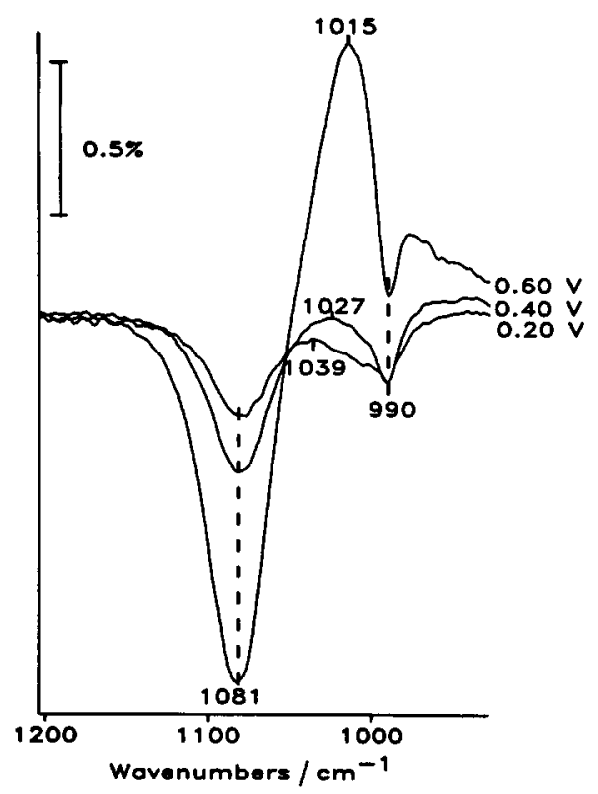

Fig. 3. Infrared spectra collected in situ as a function of electrode potential for the same solution as Fig. 2. The base potential used for these measurements was $-0.25 \mathrm{~V}$. Spectra were collected using p-polarized radiation, and plotted in transmittance mode.

spectral changes can be accounted for by considering potential dependent interfacial $\mathrm{pH}$ changes at platinum surfaces. Frumkin and Petry have investigated ionic equilibria at platinum electrodes [6] in aqueous solutions. They derived and verified experimentally thermodynamic expressions which relate the distribution of ionic charge at the interface to the surface charge density on the metal and the composition of the bulk solution. One conclusion reached in this study was that interfacial $\mathrm{pH}$ decreases with increasing positive potential over the double layer region. The spectroscopic data presented in this paper support these conclusions, and a recent infrared study by Kunimatsu et al. demonstrated similar trends in interfacial $\mathrm{pH}$ by following changes in the equilibrium distribution of sulfate and bisulfate adsorbed on platinum electrodes $[7,13]$. The weak potential dependent shift in the $\mathrm{PO}_{4}^{3-}$ band suggests that the anion/surface interaction is ionic in nature.

Figure 4 shows in situ spectra collected using p-polarized radiation at potentials in the oxide region for the $\mathrm{pH} 13$ solution. Bands pointing downward at $1158 \mathrm{~cm}^{-1}$, $1078 \mathrm{~cm}^{-1}$ and $939 \mathrm{~cm}^{-1}$ in Fig. 4 indicate the presence of $\mathrm{H}_{2} \mathrm{PO}_{4}^{-}$at the more positive potential. Spectra collected over this potential range using s-polarized radiation show the appearance of bands positioned at similar energy but reduced in intensity, suggesting that $\mathrm{H}_{2} \mathrm{PO}_{4}^{-}$is formed in the bulk solution and not confined entirely to the interfacial layer. The spectra show that $\mathrm{PO}_{4}^{3-}$ is converted to the diprotic form of the ion, indicating that the $\mathrm{pH}$ in the thin layer decreases markedly at potentials in the oxide region. The decrease in $\mathrm{pH}$ can be accounted for by 


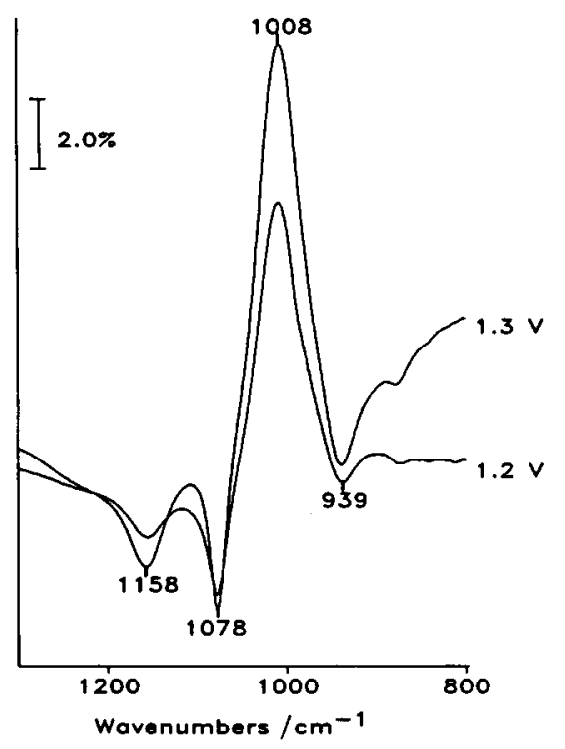

Fig. 4. Infrared spectra collected in situ at potentials in the oxide region for the $\mathrm{pH} 13$ solution using p-polarized radiation. Spectra are plotted in transmittance mode.

accumulation of hydrogen ions in the thin layer owing to water oxidation at these potentials. Similar observations have been reported for experiments at platinum in acetate and carbonate buffers [14]. In these studies, the observed $\mathrm{pH}$ change could be varied by adjusting the electrode-window distance to permit greater diffusion of ions between the thin layer and the bulk.

Analogous trends are observed at $\mathrm{pH} 10$, where losses in $\mathrm{HPO}_{4}^{2-}$ are offset by gains in $\mathrm{H}_{2} \mathrm{PO}_{4}^{-}$as the electrode potential becomes more positive. Figure 5 shows in situ infrared spectra collected using p-polarized and s-polarized radiation for a 0.1 $\mathrm{M} \mathrm{Na}_{3} \mathrm{PO}_{4}$ solution at $\mathrm{pH} 10$. Bands due to $\mathrm{HPO}_{4}^{2-}$ and $\mathrm{H}_{2} \mathrm{PO}_{4}^{-}$appear in the spectrum collected using p-polarized radiation and are shifted in energy slightly compared to spectra of the free ions. Weak bands appear in the spectrum collected using s-polarized radiation and are positioned at energies appropriate for free $\mathrm{HPO}_{4}^{2-}$ and $\mathrm{H}_{2} \mathrm{PO}_{4}^{-}$. The appearance of bands in the s-polarized spectrum indicates that changes occur in the composition of the thin layer between the electrode and zinc selenide window, and suggests that bands appearing in the p-polarized spectrum do not arise entirely from adsorbed species. Changes in the composition of the thin layer may arise from double layer charging, or may result from formation of surface oxides. The latter process would decrease the $\mathrm{pH}$ in the layer and shift the $\mathrm{H}_{2} \mathrm{PO}_{4} / \mathrm{HPO}_{4}^{2-}$ equilibrium toward formation of $\mathrm{H}_{2} \mathrm{PO}_{4}^{-}$. The complex nature of the upward extending band appearing at about $1093 \mathrm{~cm}^{-1}$ should be noted. Both $\mathrm{H}_{2} \mathrm{PO}_{4}^{-}$and $\mathrm{HPO}_{4}^{2-}$ have absorption bands centered at $1077 \mathrm{~cm}^{-1}$; thus, the shape of the band in the difference spectrum will appear distorted relative to the bands in 


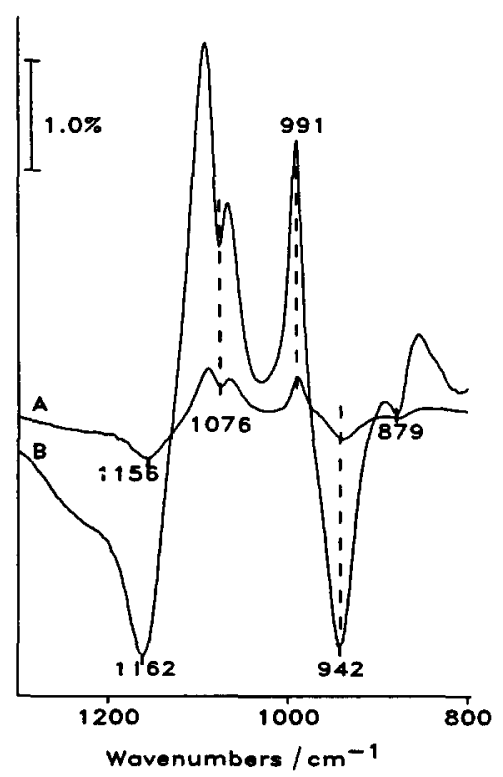

Fig. 5. Infrared spectra collected in situ at $+0.6 \mathrm{~V}$ for a solution containing $0.1 \mathrm{M} \mathrm{Na}{ }_{3} \mathrm{PO}_{4}$ at $\mathrm{pH} 10$ using (A) s-polarized and (B) p-polarized radiation. The base potential was $-0.25 \mathrm{~V}$. Spectra are plotted in transmittance mode.

transmission spectra. Superimposed on the broad upward extending band positioned at about $1093 \mathrm{~cm}^{-1}$ is a weaker band which extends downward at about 1076 $\mathrm{cm}^{-1}$. The $1077 \mathrm{~cm}^{-1}$ band for $\mathrm{H}_{2} \mathrm{PO}_{4}^{-}$is sharper than the band for $\mathrm{HPO}_{4}^{2-}$ (Figs. $1 \mathrm{~B}$ and $\mathrm{C}$ ); thus, it is likely that the $1076 \mathrm{~cm}^{-1}$ band is due to $\mathrm{H}_{2} \mathrm{PO}_{4}^{-}$formed at the more positive potential, and that the band appearing at $1093 \mathrm{~cm}^{-1}$ is due to $\mathrm{HPO}_{4}^{2-}$ vibrations, but appears shifted in position by the spectral subtraction rather than surface perturbations.

Potential dependent spectra collected using p-polarized radiation for the $\mathrm{pH} 10$ solution are shown in Fig. 6. The $\mathrm{HPO}_{4}^{2-}$ concentration is observed to decrease with increasing positive potential while the $\mathrm{H}_{2} \mathrm{PO}_{4}^{-}$concentration increases, suggesting that the $\mathrm{pH}$ in the thin layer becomes lower at more positive electrode potentials. The overall decrease in interfacial $\mathrm{pH}$ with increasing positive potential observed for phosphate solutions at $\mathrm{pH} 10$ is consistent with the general trends observed using the $\mathrm{pH} 13$ solution. Preliminary studies using acidic phosphate solutions indicate that similar potential dependent $\mathrm{pH}$ changes are observed, and a detailed study of $\mathrm{H}_{3} \mathrm{PO}_{4}$ adsorption is under way.

At this point an interesting comparison can be made regarding potential dependent interfacial $\mathrm{pH}$ changes at platinum and silver electrodes. A SERS study of phosphate adsorbed on silver electrodes has appeared which indicates that the $\mathrm{pH}$ at the silver surface decreases with decreasing positive potential [8]. In strongly hasic media where $\mathrm{PO}_{4}^{3-}$ is dominant, the more acidic $\mathrm{HPO}_{4}^{2-}$ is formed when the 


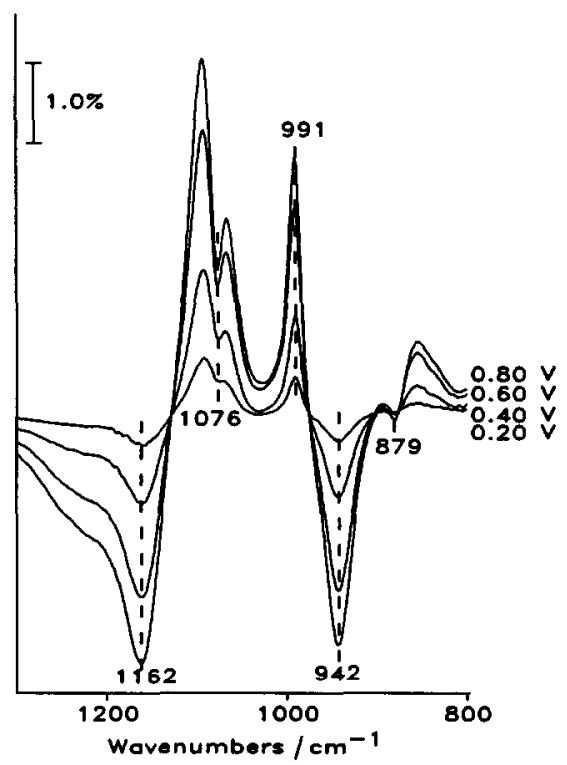

Fig. 6. Infrared spectra collected in situ as a function of electrode potential for the same solution as Fig. 5. The base potential used for these measurements was $-0.25 \mathrm{~V}$. Spectra were collected using p-polarized radiation, and plotted in transmittance mode.

potential is swept from a rest potential in the silver oxide region to more negative potentials. This is exactly the opposite of what is observed on platinum surfaces.

In conclusion, the $\mathrm{pH}$ at the platinum/solution interface is observed to decrease with increasing positive potential in alkaline solutions. The potential dependent $\mathrm{pH}$ changes obscrved in these studies are consistent with thcories concerning the interfacial properties of hydrogen adsorbing metals [6]. Such potential dependent $\mathrm{pH}$ changes can have important consequences when studying the reactivity of compounds which are sensitive to $\mathrm{pH}$.

\section{ACKNOWLEDGEMENTS}

Portions of this work were supported by a grant from the Rackham Foundation of The University of Michigan. C.K. gratefully acknowledges support from the Cammille \& Henry Dreyfus Foundation Distinguished New Faculty Program and a Dow Corning Assistant Professorship.

\section{References}

1 M.A. Habib and J.O'M. Bockris, J. Electrochem. Soc., 130 (1983) 2510.

2 M.A. Habib and J.O'M. Bockris, J. Electrochem. Soc., 132 (1985) 108.

3 G. Dryhurst, K.M. Kadish, F. Scheller and R. Renneberg, Biological Electrochemistry, Academic Press, New York, 1982. 
4 G. Horanyi and E.M. Rizmayer, J. Electroanal. Chem., 36 (1972) 496.

5 G. Horanyi, E.M. Rizmayer and G. Inzelt, J. Electroanal. Chem., 93 (1978) 183.

6 A.N. Frumkin and O.A. Petry, Electrochim. Acta, 15 (1970) 391.

7 K. Kunimatsu, M.G. Samant and H. Seki, J. Electroanal. Chem., 258 (1989) 163.

8 P.B. Dorain, K.U. Von Raben and R.K. Chang, Surf. Sci., 148 (1984) 439.

9 H. Seki, K. Kunimatsu and W.G. Golden, Appl. Spectrosc., 39 (1985) 437.

10 A.C. Chapman and L.E. Thirlwell, Spectrochim. Acta, 20 (1964) 937.

11 B.J. Hathaway and A.E. Underhill, J. Chem. Soc., (1961) 3091.

12 K. Nakamoto, Infrared Spectra of Inorgainc and Coordination Compounds, 4th ed., Wiley, New York, 1986.

13 K. Kunimatsu, M.G. Samant, H. Seki and M.R. Philpott, J. Electroanal. Chem., 243 (1988) 203.

14. I.T. Bae, D.A. Scherson and E.B. Yeager, Anal. Chem., 62 (1990) 45. 